\title{
Unexpected Airway Obstruction Caused by Bilateral Hypoglossal Nerve Palsy Following Second Radical Neck Dissection
}

\author{
Shinichi Ito ${ }^{1}$, Shigeki Fujiwara ${ }^{1}$, Tomoaki Yatabe ${ }^{2}$, Koichi Yamashita ${ }^{2}$, Takeshi Yokoyama ${ }^{1}$ \\ ${ }^{1}$ Department of Dental Anesthesiology, Faculty of Dental Science, Kyushu University, Fukuoka, Japan; ${ }^{2}$ Department of Anesthesi- \\ ology and Critical Care Medicine, Kochi Medical School Hospital, Nankoku, Japan. \\ Email: ito@dent.kyushu-u.ac.jp
}

Received February $21^{\text {st }}$, 2013; revised March $30^{\text {th }}, 2013$; accepted April $15^{\text {th }}, 2013$

Copyright (C) 2013 Shinichi Ito et al. This is an open access article distributed under the Creative Commons Attribution License, which permits unrestricted use, distribution, and reproduction in any medium, provided the original work is properly cited.

\begin{abstract}
A 67-year-old woman underwent right radical neck dissection for cervical lymph node metastasis from maxillary gingival carcinoma. Two months later, metastasis in the left superior internal jugular lymph nodes were discovered, and left radical neck dissection was performed. Postoperatively, airway obstruction occurred despite performing extubation after confirming that the patient had fully recovered from anesthesia. Bilateral hypoglossal nerve palsy was diagnosed and the patient was reintubated. After extubation on the following day, airway obstruction was relieved, but slurred speech and impaired swallowing were persistent. In view of this, hypoglossal nerve function should be examined before the second radical neck dissection on the contralateral side.
\end{abstract}

Keywords: Hypoglossal Nerve Injuries; Neck Dissection; Airway Obstruction; Stuttering; Deglutition Disorders

\section{Introduction}

Hypoglossal nerve palsy can occur with tumors, trauma, stroke, multiple sclerosis, Guillan Barre neuropathy infection [1] and head and neck injury [2]. Presence of a tumor or a cyst is the most leading cause. In addition, there are reports of hypoglossal nerve palsy after surgery; carotid endarterectomy [3,4] or atlanto-axial fixation [5]. However, unilateral hypoglossal palsy often goes unnoticed due to unremarkable symptoms. When bilateral hypoglossal nerve palsy occurs, serious clinical symptoms including airway obstruction due to tongue root depression, stuttering and deglutition disorder can develop [3]. We present a case of airway obstruction caused by bilateral hypoglossal nerve palsy following second radical neck dissection and subsequent reintubation.

\section{Case Report}

The patient was a 67-year-old woman (45 kg, $151 \mathrm{~cm}$ ). Medical and family histories were unremarkable. The partial maxillary resection and the right radical neck dissection were performed 2 months ago for the maxillary gingival cancer and the metastasis in the right submandibular lymph nodes. However, metastases were found also in the left superior internal jugular lymph nodes, and the left radical neck dissection was scheduled.

Oral diazepam $10 \mathrm{mg}$ was administered as premedication 1 hour before the operation. Midazolam $4 \mathrm{mg}$ was administered intravenously, and slow anesthetic induction was employed using sevoflurane, gradually increased to $7 \%$ in oxygen. Anesthesia was maintained with $1 \%$ $3 \%$ sevoflurane in oxygen at $4 \mathrm{~L} / \mathrm{min}$ and fentanyl 0.2 $\mathrm{mg}$. The lymph nodes were adherent to the left internal jugular vein, the left sternocleidmastoid muscle and the left posterior belly of the digastric muscle. Especially, adhesion was firm at the bifurcation of the common carotid artery, and the region around the metastatic lymph nodes was bluntly dissected. The left superior thyroid artery was unavoidably severed during this procedure. The duration of operation was 3 hours and 5 minutes. The patient fully awoke and displayed normal handgrip after emergence from anesthesia. The patient's blood pressure was 125/55 mmHg and heart rate was 75 beats/ min. The percutaneous saturation of $\mathrm{O}_{2}\left(\mathrm{SpO}_{2}\right)$ was 100 $\%$. Tidal volume was $360 \mathrm{ml}$ and respiratory rate was 16 breaths/min. Therefore, we extubated her. 5 minutes after extubation, however, the $\mathrm{SpO}_{2}$ decreased to $65 \%$ suddenly, and cyanosis developed. Loosening the wound 
compression around the neck and securing the airway was followed by recovery of $\mathrm{SpO}_{2}$ to $99 \%$ within 1 minute. However, $\mathrm{SpO}_{2}$ again decreased to $65 \% 10$ minutes after extubation. Hypoglossal nerve palsy was diagnosed since airway obstruction occurred even after removing the outer compression of the wound and the patient could not pronounce well due to lingual dyskinesia. Thus, the patient was reintubated and admitted in intensive care unit. After re-extubation was performed on the following day, no airway obstruction occurred. However, stuttering and deglutition disorder still remained.

\section{Discussion}

We experienced a case of airway obstruction after second radical neck dissection. The patient opened her eyes, and her handgrip was normal before extubation. There was no respiratory suppression by fentanyl, since respiratory rate was stable at 16 breaths/min. However, there was occurrence of sudden airway obstruction after extubation.

Hypoglossal nerve is a pure motor nerve supplying the lingual muscles and part of the pharyngeal musculature [6]. Therefore, hypoglossal nerve palsy caused by severing the hypoglossal nerve leads to lingual dyskinesia. In this case, considering, that airway obstruction and wound compression occurred simultaneously, it was thought that airway obstruction might have resulted from a combination of tongue root edema caused by the operation and outer wound compression. However, hypoglossal nerve palsy was diagnosed since airway obstruction occurred again after removing the outer compression of the wound, and pronounced lingual dyskinesia was observed.

It has been reported that recovery from upper airway obstruction occurred following hypoglossal nerve stimulation $[7,8]$. This shows that the hypoglossal nerve is important for contracting the muscles of the tongue root in order to prevent upper airway obstruction. Bilateral hypoglossal nerve palsy results in airway obstruction in the supine position. In unilateral hypoglossal nerve palsy, the tip of the tongue is deflected to the affected side when the tongue is protruded [1]. The tongue tip is deflected to the unaffected side and dysphemia and dysphagia are mild in the resting state. Unilateral hypoglossal nerve palsy thus often goes unnoticed. In the present case, right radical neck dissection was performed for right submandibular lymph node metastasis 2 months earlier, and no clear symptoms of hypoglossal nerve palsy were noted before the second operation. Airway obstruction occurred following a second left radical dissection after the patient was fully recovered from anesthetic. When extubation was performed the following day, airway obstruction was relieved, while dysphemia and dysphagia due to tongue dyskinesia continued to be present. Since hypoglossal nerve palsy was not relieved, palsy might have resulted from perioperative severing of hypoglossal nerves bilaterally.

Hypoglossal nerve palsy appearance after surgery is rare complication. Nonetheless, there are a few reports related to endotracheal intubation $[9,10]$ or use of laryngeal mask airway [11,12]. In addition, there are slim chances of injuring hypoglossal nerve bilaterally in surgical procedure. In this case, however, the patient unfortunately had metastasis in the cervical lymph nodes by hypoglossal nerve on both sides, and hypoglossal nerves were severed bilaterally. Bilateral hypoglossal nerve palsy following bilateral radical neck dissection results from severing the hypoglossal nerve, and such paralysis is permanent. Bilateral hypoglossal palsy results in postoperative airway obstruction in the supine position, in addition to dysphemia and dysphagia. Therefore, assessment of unilateral hypoglossal nerve palsy status is important when a patient with a history of neck surgery or injury undergoes contralateral radical neck dissection. Potential candidates for bilateral hypoglossal nerve palsy from bilateral neck dissection require sufficient airway management to prevent and minimize postoperative complications.

\section{REFERENCES}

[1] B. Olzowy, S. Lorenzl and R. Guerkov, "Bilateral and Unilateral Internal Carotid Artery Dissection Causing Isolated Hypoglossal Nerve Palsy: A Case Report and Review of the Literature," European Archives of Oto-RhinoLaryngology and Head \& Neck, Vol. 263, No. 4, 2006, pp. 390-393. doi:10.1007/s00405-005-1005-3

[2] S. Omura, Y. Nakajima, S. Kobayashi, S. Ono and K. Fujita, "Oral Manifestations and Differential Diagnosis of Isolated Hypoglossal Nerve Palsy: Report of Two Cases," Oral Surgery, Oral Medicine, Oral Pathology, Oral Radiology, and Endodontology, Vol. 84, No. 6, 1997, pp. 635-640. doi:10.1016/S1079-2104(97)90365-6

[3] T. E. Bageant, D. Tondini and D. Lysons, "Bilateral Hypoglossal-Nerve Palsy Following a Second Carotid Endarterectomy,” Anesthesiology, Vol. 43, No. 5, 1975, pp. 595-596. doi:10.1097/00000542-197511000-00026

[4] J. P. Levelle and O. A. Martinez, "Airway Obstruction after Bilateral Carotid Endarterectomy,” Anesthesiology, Vol. 63, No. 2, 1985, pp. 220-222. doi:10.1097/00000542-198508000-00024

[5] J. T. Hong, S. W. Lee, B. C. Son, J. H. Sung, I. S. Kim and C. K. Park, "Hypoglossal Nerve Palsy after Posterior Screw Placement on the C-1 Lateral Mass," Journal of neurosurgery. Spine, Vol. 5, No. 1, 2006, pp. 83-85. doi:10.3171/spi.2006.5.1.83

[6] W. J. S. Krieg, “Functional Neuroanatomy,” Blakiston, New York, 1953, pp. 73-77.

[7] G. S. Goding Jr., D. W. Eisele, R. Testerman, P. L. Smith, K. Roertgen and A. R. Schwartz, "Relief of Upper Air- 
way Obstruction with Hypoglossal Nerve Stimulation in the Canine," Laryngoscope, Vol. 108, No. 2, 1998, pp. 162-169. doi:10.1097/00005537-199802000-00003

[8] J. Ilomaki, G. A. Baer, T. Karhuketo, P. Talonen and H. Puhakka, "Pharyngeal Patency Caused by Stimulation of the Hypoglossal Nerve in Anaesthesia-Relaxed Patients," Acta Oto-Laryngologica, Vol. 117, No. s529, 1997, pp. 210-211. doi:10.3109/00016489709124124

[9] M. A. Condado, D. Morais, J. Santos, J. Alonso-Vielba and V. Miyar, "Hypoglossal Nerve Paralysis after Intubation and Direct Laryngoscopy," Acta Otorrinolaringologica Espanola, Vol. 45, No. 6, 1994, pp. 477-479.

[10] M. Streppel, G. Bachmann and E. Stennert, "Hypoglossal
Nerve Palsy as a Complication of Transoral Intubation for General Anesthesia,” Anesthesiology, Vol. 86, No. 4, 1997, p. 1007. doi:10.1097/00000542-199704000-00036

[11] K. Nagai, C. Sakuramoto and F. Goto, "Unilateral Hypoglossal Nerve Paralysis Following the Use of the Laryngeal Mask Airway,” Anaesthesia, Vol. 49, No. 7, 1994, pp. 603-604.

[12] M. Sommer, M. Schuldt, U. Runge, S. Gielen-Wijffels and M. A. Marcus, "Bilateral Hypoglossal Nerve Injury Following the Use of the Laryngeal Mask without the Use of Nitrous Oxide,” Acta Anaesthesiologica Scandinavica, Vol. 48, No. 3, 2004, pp. 377-378. doi:10.1111/j.0001-5172.2004.0332.x 